\title{
Detection of 'best' positive end-expiratory pressure derived from electrical impedance tomography parameters during a decremental positive end-expiratory pressure trial
}

\author{
Paul Blankman ${ }^{1}$, Djo Hasan², Groot Jebbink Erik ${ }^{3}$ and Diederik Gommers ${ }^{1 *}$
}

\begin{abstract}
Introduction: This study compares different parameters derived from electrical impedance tomography (EIT) data to define 'best' positive end-expiratory pressure (PEEP) during a decremental PEEP trial in mechanically-ventilated patients. 'Best' PEEP is regarded as minimal lung collapse and overdistention in order to prevent ventilator-induced lung injury.
\end{abstract}

Methods: A decremental PEEP trial (from 15 to $0 \mathrm{~cm} \mathrm{H}_{2} \mathrm{O}$ PEEP in 4 steps) was performed in 12 post-cardiac surgery patients on the ICU. At each PEEP step, EIT measurements were performed and from this data the following were calculated: tidal impedance variation (TIV), regional compliance, ventilation surface area (VSA), center of ventilation (COV), regional ventilation delay (RVD index), global inhomogeneity (GI index), and intratidal gas distribution. From the latter parameter we developed the ITV index as a new homogeneity parameter. The EIT parameters were compared with dynamic compliance and the $\mathrm{PaO}_{2} / \mathrm{FiO}_{2}$ ratio.

Results: Dynamic compliance and the $\mathrm{PaO}_{2} / \mathrm{FiO}_{2}$ ratio had the highest value at 10 and $15 \mathrm{~cm} \mathrm{H} \mathrm{H}_{2} \mathrm{O}$ PEEP, respectively. TIV, regional compliance and VSA had a maximum value at $5 \mathrm{~cm} \mathrm{H}_{2} \mathrm{O}$ PEEP for the non-dependent lung region and a maximal value at $15 \mathrm{~cm} \mathrm{H}_{2} \mathrm{O}$ PEEP for the dependent lung region. $\mathrm{Gl}$ index showed the lowest value at $10 \mathrm{~cm} \mathrm{H} \mathrm{H}_{2} \mathrm{O}$ PEEP, whereas for COV and the RVD index this was at $15 \mathrm{~cm} \mathrm{H}_{2} \mathrm{O}$ PEEP. The intratidal gas distribution showed an equal contribution of both lung regions at a specific PEEP level in each patient.

Conclusion: In post-cardiac surgery patients, the ITV index was comparable with dynamic compliance to indicate 'best' PEEP. The ITV index can visualize the PEEP level at which ventilation of the non-dependent region is diminished, indicating overdistention. Additional studies should test whether application of this specific PEEP level leads to better outcome and also confirm these results in patients with acute respiratory distress syndrome.

\section{Introduction}

Mechanical ventilation acts as a stress raiser to lung tissue adjacent to collapsed tissue in the dependent lung and the risk of alveolar hyperinflation in the nondependent lung [1]. An alveolar recruitment maneuver and the use of positive end-expiratory pressure (PEEP) are applied to open up and to keep open the atelectatic lung tissue in an attempt to minimize this stress and over-distention.

\footnotetext{
* Correspondence: d.gommers@erasmusmc.nl

'Department of Intensive Care Adults, Erasmus MC Rotterdam, Room H623, 's Gravendijkwal 230, Rotterdam 3015 CE, The Netherlands

Full list of author information is available at the end of the article
}

The original definition of the best PEEP as proposed by Suter et al. is the PEEP level with the best compromise between lung aeration and circulatory depression [2]; circulatory depression is caused by compression of capillaries due to hyperinflation. Tusman et al. performed an incremental and decremental PEEP trial in eight volumecontrolled ventilated surfactant-depleted pigs; they showed that calculation of dead space detected early signs of lung collapse, which correlated well with findings on computed tomography $(\mathrm{CT})$ [3]. In a second study, these authors reported that continuous compliance monitoring could identify the onset of alveolar collapse as confirmed by $\mathrm{CT}$, as well as changes in partial arterial oxygen pressure

\section{Biomed Central}

(c) 2014 Blankman et al.; licensee BioMed Central Ltd. This is an Open Access article distributed under the terms of the Creative Commons Attribution License (http://creativecommons.org/licenses/by/2.0), which permits unrestricted use, distribution, and reproduction in any medium, provided the original work is properly cited. 
$\left(\mathrm{PaO}_{2}\right)$ values [4]. Another experimental study, using an oleic acid-induced acute lung injury (ALI) model, showed that minimizing elastance of the respiratory system could be used to titrate PEEP settings [5]. Maisch et al. performed an incremental and decremental PEEP trial in 20 anesthetized patients undergoing elective surgery and confirmed that dynamic compliance and dead-space calculations were able to detect alveolar collapse and/or overdistention, whereas functional residual capacity (FRC) and $\mathrm{PaO}_{2}$ changes were less sensitive [6]. From these studies it has been concluded that dynamic compliance and deadspace calculations are the most reliable global parameters to define the best PEEP at the bedside.

$\mathrm{CT}$ is regarded as the gold standard to assess the effect of a recruitment maneuver and the applied PEEP on aeration of the lung $[7,8]$. However, the obvious drawbacks of repeated CT scans (that is, transfer of the mechanically ventilated patient and excessive radiation exposure) reduce the application of CT as a tool for assessment of PEEP settings. On the other hand, electrical impedance tomography (EIT) is a real-time bedside monitoring tool, which has proven to correlate well with $\mathrm{CT}$ for assessment of changes in gas volume and tidal volume [9-11].

Several EIT parameters have been developed to collect more data on ventilation distribution in order to optimize ventilator settings [12-15]. The present study examines whether one specific EIT parameter is able to describe the optimal PEEP level at the bedside; for this, we defined the best PEEP as the PEEP level with minimal lung collapse and minimal over-distention.

\section{Materials and methods \\ Study population}

Included in this study were 12 mechanically ventilated post cardiac surgery patients admitted to the cardiothoracic intensive care unit. Data for the present study were used in an earlier study that analyzed the effect of a decremental PEEP trial on ventilation distribution with EIT measured at two different thoracic levels [16]. Informed consent was obtained from the patient or a legal representative. Using data from this latter study, we reanalyzed data of the EIT measurements made just above the diaphragm only, as this part of the lung is at most risk for formation of atelectasis in mechanically ventilated patients in the supine position. The Medical Ethical Committee Rotterdam approved the entire study protocol.

\section{Study protocol and measurements}

A 16-electrode silicon belt (EIT evaluation kit 2, Dräger, Lübeck, Germany) was placed around the patient's thoracic cage between the 6th and 7th intercostal spaces [16]. Patients were ventilated with pressure-controlled ventilation (PCV) (Engström Carestation, GE Healthcare, Madison, WI, USA) and, throughout the entire study period, the inspiratory pressure above PEEP, the Inspiration/ expiration (I/E) ratio, frequency and inspired oxygen fraction $\left(\mathrm{FiO}_{2}\right)$ remained unchanged.

In this study we performed a recruitment maneuver in which mechanical ventilation was continued with a pressure amplitude of $20 \mathrm{~cm} \mathrm{H}_{2} \mathrm{O}$ while PEEP was rapidly increased from 5 to $20 \mathrm{~cm} \mathrm{H}_{2} \mathrm{O}$ in incremental steps of $5 \mathrm{~cm} \mathrm{H}_{2} \mathrm{O}$ : thus, a peak pressure of $40 \mathrm{~cm} \mathrm{H}_{2} \mathrm{O}$ for a 40-s period, as long as blood pressure remained stable. Thereafter, PEEP was decreased to $15 \mathrm{~cm} \mathrm{H}_{2} \mathrm{O}$ and the pressure amplitude was decreased from 20 to $10 \mathrm{~cm} \mathrm{H}_{2} \mathrm{O}$. A PEEP level of $15 \mathrm{~cm} \mathrm{H}_{2} \mathrm{O}$ was applied for 15 minutes to achieve a steady state. Thereafter, a decremental PEEP trial was performed from 15 to $0 \mathrm{~cm} \mathrm{H}_{2} \mathrm{O}$ PEEP in steps of $5 \mathrm{~cm} \mathrm{H}_{2} \mathrm{O}$. Each PEEP level was applied for 10 to 20 minutes (depending on hemodynamic stability and blood gas analyses). At the end of each PEEP step, EIT, $\mathrm{PaO}_{2} / \mathrm{FiO}_{2}$ ratio and dynamic compliance (tidal volume divided by pressure above PEEP) were calculated.

\section{EIT data analysis}

EIT data were recorded with a sample rate of $20 \mathrm{~Hz}$ and were analyzed using dedicated software (EITdiag, Dräger Medical, Lübeck, Germany). For each PEEP step a stable phase with 10 to 20 consecutive breaths was selected. The EIT signals of these breaths are filtered using a lowpass filter set on 40 beats per minute to minimize signals induced by the cardiovascular system. From the filtered signals a ventilation distribution map was created for each PEEP step (Figure 1). The surface of the distribution maps was standardized, using the largest EIT image acquired during the PEEP trial for each patient. The EIT signals in the distribution maps are used to calculate the tidal impedance variation (TIV), ventilation surface area (VSA), center of gravity (COG), and the global inhomogeneity (GI index). In order to reliably calculate the intratidal gas distribution, all filtered signals were resampled at $40 \mathrm{~Hz}$ to divide the inspiratory part of the TIV curve more accurately into 8-iso volume steps. To calculate the different parameters, the defined surface area was divided into two equal regions of interest, that is, the dependent and non-dependent regions (Figure 1).

\section{Calculated EIT parameters}

EIT measures changes in electrical impedance between electrode pairs. After adequate filtering of EIT signals, the measured impedance changes represent the inspiration and expiration by means of TIV (formula 1), which correlates well with tidal volume $[9,11,17,18]$.

$$
T I V=\text { Impedance }_{\text {max }}-\text { Impedance }_{\min }
$$



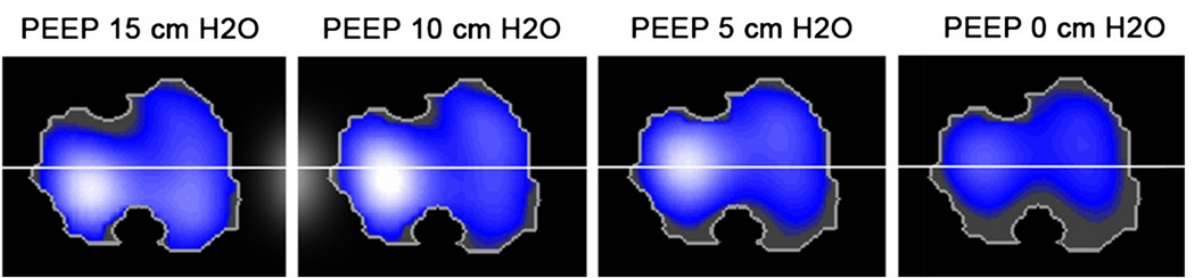

Figure 1 Example of electrical impedance tomography (EIT) image reconstruction. Shown is the distribution of impedance to the dependent and non-dependent lung regions of one representative patient. The lighter the color, the higher the impedance and the more aerated the lung region. The surface area used in all calculations at every positive end-expiratory pressure (PEEP) step is equal to the largest surface area. The EIT image is divided into two equal regions of interest represented by the white line; all EIT modalities are calculated using this setup. Decreasing the PEEP value resulted in a decrease in aeration of the lungs, especially in the dependent region.

The second EIT parameter to be calculated is regional compliance [12]. Calculation of regional compliance is similar to that of dynamic compliance; however, for dynamic compliance tidal volume is divided by pressure amplitude whereas for regional compliance TIV is divided by pressure amplitude. As we did not connect the EIT device to the ventilator, we were unable to calculate regional compliance using EITdiag software. Therefore, we divided the TIV into dependent and non-dependent lung regions by the EITdiag-generated ventilation distribution map, based on the pressure above PEEP (formula 2). A decrease in regional compliance with increases in PEEP indicates that the lung is hyperinflated, whereas a decrease in regional compliance with decreases in PEEP indicates alveolar collapse.

$$
\text { Compliance }_{\text {region }}=\frac{T I V_{\text {region }}}{\text { Pressureabove PEEP }}
$$

\section{(TIV = Tidal Impedance Variation)}

Using EITdiag software, we calculated the VSA. For this, the number of pixels with an EIT signal in the generated ventilation distribution map was counted for both lung regions. During the recruitment maneuver, the number of ventilated pixels per region is divided by the total number of ventilated pixels in the ventilation distribution map, assuming that all recruitable lung tissue was open at the end of recruitment. In this way, regional ventilation distribution is expressed as a percentage of the maximum ventilated pixels at the end of recruitment. After increasing PEEP levels, higher VSA values indicate alveolar recruitment whereas after decreasing PEEP levels higher VSA values indicate that the lungs were hyperinflated during the previous PEEP level.

In the present study, calculation of the regional ventilation delay (RVD) index describes the percentage of time needed to reach a threshold of $40 \%$ of the regional impedance changes, as compared with the total inspiratory time (formula 3 ) $[15,19]$. This calculation was not performed using the EITdiag software. Large differences in RVD between both lung regions indicate that the lungs are inhomogeneously ventilated.

$$
R V D_{i}=\frac{\Delta t_{i}^{40 \%}}{t_{\text {max }}-t_{\text {min }}} \times 100 \%
$$

$(R V D=$ Regional Ventilation Delay index; $i=$ region; $\Delta=$ delta)

The intratidal gas distribution was analyzed according to Löwhagen et al. [14] (formula 4), which is integrated in the EITdiag software. To calculate the intratidal gas distribution the inspiratory part of the global TIV curve is divided into eight iso-volume parts. Thereafter, the eight corresponding time points are translated to the regional TIV curves. Using this technique, we calculated the percentile contribution of the dependent and nondependent regions to the inspiration. Thereafter, we developed the intratidal gas distribution index (ITV index) to evaluate whether the lung is homogeneously ventilated. The ITV index is calculated by dividing the ITV of the non-dependent lung region by the ITV of the dependent region (formula 5). An ITV index of 1 indicates an equal distribution of ventilation to the dependent and nondependent lung regions.

$$
\begin{aligned}
& \text { Fractional regional ITV } V_{1-8}=\frac{I T V_{1-8} T I V_{R O I}}{I T V_{1-8} T I V_{\text {Global }}} \\
& I T V \text {-index }=\frac{\sum_{\mathrm{r} 1, \mathrm{E}} I T V \text { non-dependent }}{\sum_{\mathrm{r} 1, \mathrm{E}} I T V \text { dependent }}
\end{aligned}
$$

(ITV = Intratidal Gas Distribution; TIV = Tidal Impedance Variation; $R O I=$ Region of Interest; $t=$ iso-volume part)

The COV reflects the distribution of tidal ventilation in the ventral-to-dorsal direction [13] (formula 6). Therefore, the TIV of the dependent region is divided by the total TIV of the EIT image. When most of the tidal ventilation distributes to the dependent lung region this results in a small COV value. We constructed a plot of the centers of ventilation to visualize the shifts 
in regional lung ventilation in the anterior-to-posterior direction during the PEEP trial.

$$
C O V=\frac{T I V_{\text {dorsal }}}{T I V_{\text {total }}}
$$

$(C O V=$ Center of Ventilation; $T I V=$ Tidal Impedance Variation)

The GI index, developed by Zhao et al., quantifies ventilation distribution in the lungs $[20,21]$. Therefore, the tidal impedance difference per pixel is subtracted by the median tidal impedance difference of the lung. Thereafter, the result of this subtraction is divided by the total impedance changes of all pixels in order to normalize the calculated values (formula 7). Thus, the GI index calculates the variance in impedance per pixel as compared with the total EIT image. The smaller the GI index, the more homogeneous the lung ventilation. This calculation is integrated in the EITdiag software.

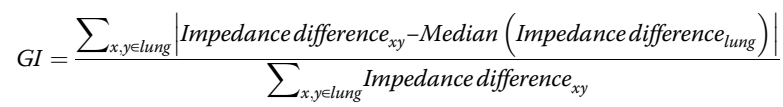

GI index formula: ( $x$ and $y$ describe the location of the pixel on the $x$ and $y$ axes; $\in=$ element of ventilated part of the EIT image)

\section{Statistical analysis}

Statistical analyses were performed using SPSS version 21 (IBM, Chicago, IL, USA). Unless specified otherwise, values are presented as means $\pm \mathrm{SD}$. Data were tested for normal distribution and homoscedasticity using the Kolmogorov-Smirnov test and the Brown-Forsythe test. If the data had a normal distribution we applied analysis of variance (ANOVA), otherwise, the independentsamples Kruskal-Wallis test was used. Differences in $\mathrm{PaO}_{2} / \mathrm{FiO}_{2}$ ratio and dynamic compliance between the PEEP steps were analyzed using mixed linear model analyses. Correlation between the $\mathrm{PaO}_{2} / \mathrm{FiO}_{2}$ ratio and ITV index was calculated using the two-tailed Spearman rho test.

All $P$-values $<0.05$ are considered to be statistically significant.

\section{Results}

Details of patient characteristics are presented in Table 1. During the entire PEEP trial, patients were ventilated with an inspiratory pressure above PEEP of $10 \pm 2 \mathrm{~cm}$ $\mathrm{H}_{2} \mathrm{O}$. A $\mathrm{PaO}_{2} / \mathrm{FiO}_{2}$ ratio $\geq 350 \mathrm{mmHg}$ was defined as an open lung; in two patients we were unable to open up the lung despite the recruitment maneuver and use of a PEEP level of $15 \mathrm{~cm} \mathrm{H}_{2} \mathrm{O}$. Figure 1 shows the distribution
Table 1 Baseline characteristics of the study population

\begin{tabular}{lc}
\hline Characteristic & Value \\
\hline Number of patients & 12 \\
Age, years & $70 \pm 9$ \\
Male:female, number & $9: 3$ \\
Weight, kg & $79 \pm 12$ \\
PBW, kg & $67 \pm 9$ \\
Height, $\mathrm{m}$ & $1.72 \pm 0.08$ \\
Body mass index & $27 \pm 4$ \\
Respiratory rate, breaths per minute & $15 \pm 1$ \\
PIP, $\mathrm{cm} \mathrm{H}_{2} \mathrm{O}$ & $25 \pm 2$ \\
$\mathrm{~V}_{\text {Te, }} \mathrm{mL}$ & $591 \pm 120$ \\
$\mathrm{~V}_{\mathrm{T}} / \mathrm{PBW}, \mathrm{mL} / \mathrm{kg}$ & $8.8 \pm 1.7$ \\
\hline
\end{tabular}

Data are presented as means \pm SD, unless stated otherwise. PBW, predicted

body weight; PIP, peak inspiratory pressure; $\mathrm{V}_{\mathrm{Te}}$, expiratory tidal volume.

of TIV for one representative patient during the decremental PEEP trial. The effects of decremental PEEP on TIV, regional compliance, VSA, COV, RVD and GI index are presented in Figure 2A-F.

Figure 3 shows the effects of the decremental PEEP trial on the $\mathrm{PaO}_{2} / \mathrm{FiO}_{2}$ ratio and dynamic compliance for the entire study population. The $\mathrm{PaO}_{2} / \mathrm{FiO}_{2}$ ratio had the highest value at $15 \mathrm{~cm} \mathrm{H}_{2} \mathrm{O}$ PEEP but showed a significant decrease after lowering PEEP from 10 to 5 to $0 \mathrm{~cm} \mathrm{H}_{2} \mathrm{O}$ compared with $15 \mathrm{~cm} \mathrm{H}_{2} \mathrm{O}$ PEEP (Figure 3A). Dynamic compliance had the highest value at $10 \mathrm{~cm}$ $\mathrm{H}_{2} \mathrm{O}$ PEEP but showed a significant decrease at a PEEP level of 0 compared with $15 \mathrm{~cm} \mathrm{H}_{2} \mathrm{O}$ (Figure 3B).

In the non-dependent lung regions, TIV (Figure 2A), regional compliance (Figure 2B) and VSA (Figure 2C) reached the maximum value at $5 \mathrm{~cm} \mathrm{H}_{2} \mathrm{O}$ PEEP. In contrast, in the dependent region TIV, VSA and regional compliance reached a maximum at the highest PEEP level applied and then decreased during the entire PEEP trial. During the decremental PEEP trial, COV increased steadily towards the anterior part of the thorax cavity, indicating loss of TIV in the dependent region (Figure 2D). During the decremental PEEP trial the RVD index increased in both lung regions and the RVD values of the non-dependent region remained significantly lower than those in the dependent region, except at zero end-expiratory pressure (Figure 2E). The GI index had the lowest values at 15 and $10 \mathrm{~cm} \mathrm{H}_{2} \mathrm{O}$ PEEP and then increased steadily at lower PEEP levels (Figure 2F), indicating more homogeneous ventilation at higher PEEP levels.

Figure 4 presents the results of intratidal gas distribution. At the highest levels of PEEP, the intratidal gas distribution to the dependent region was higher than that to the non-dependent region. Decreasing the PEEP level resulted in a higher overall gas distribution to the non-dependent region compared with the dependent 

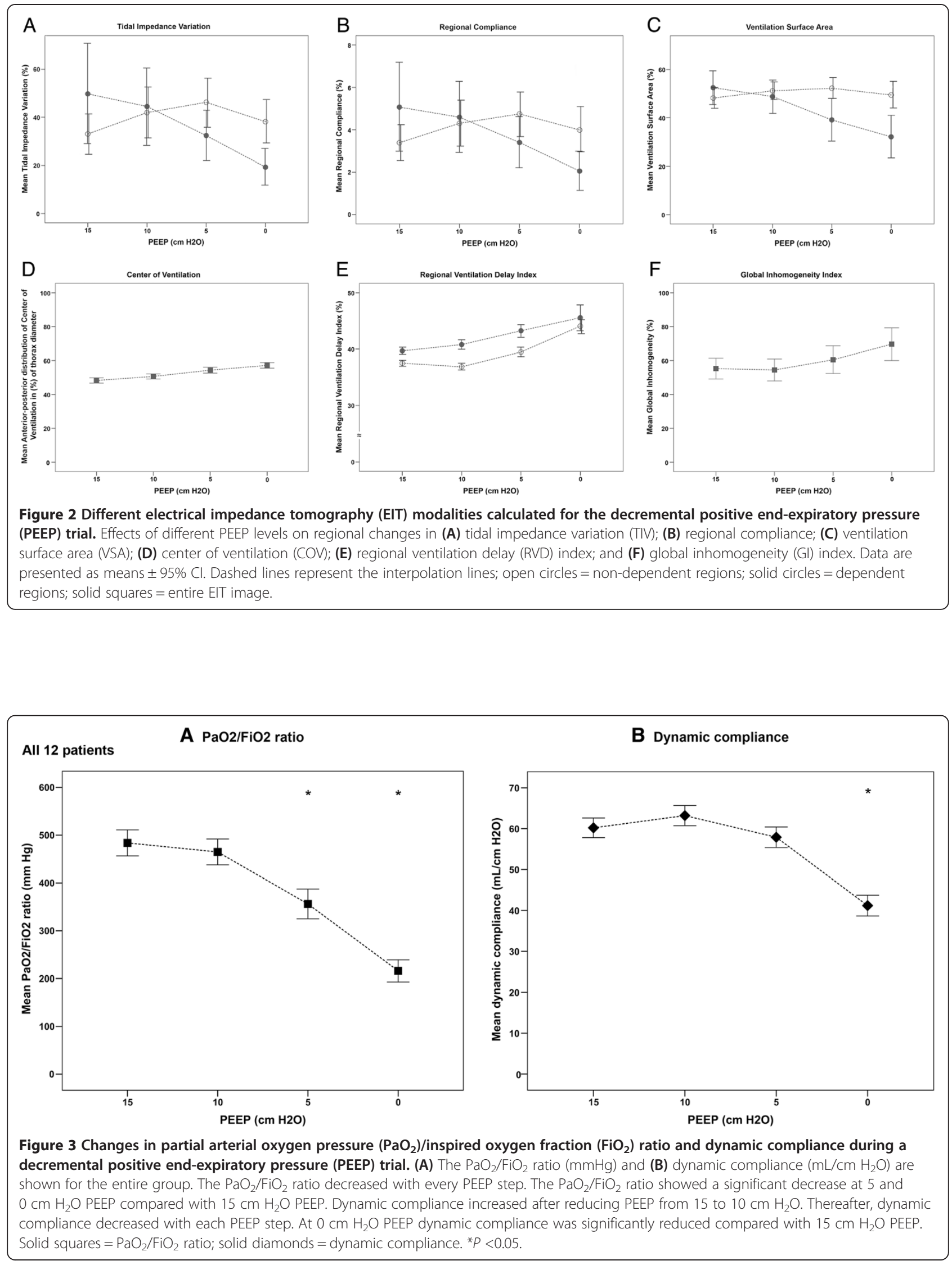


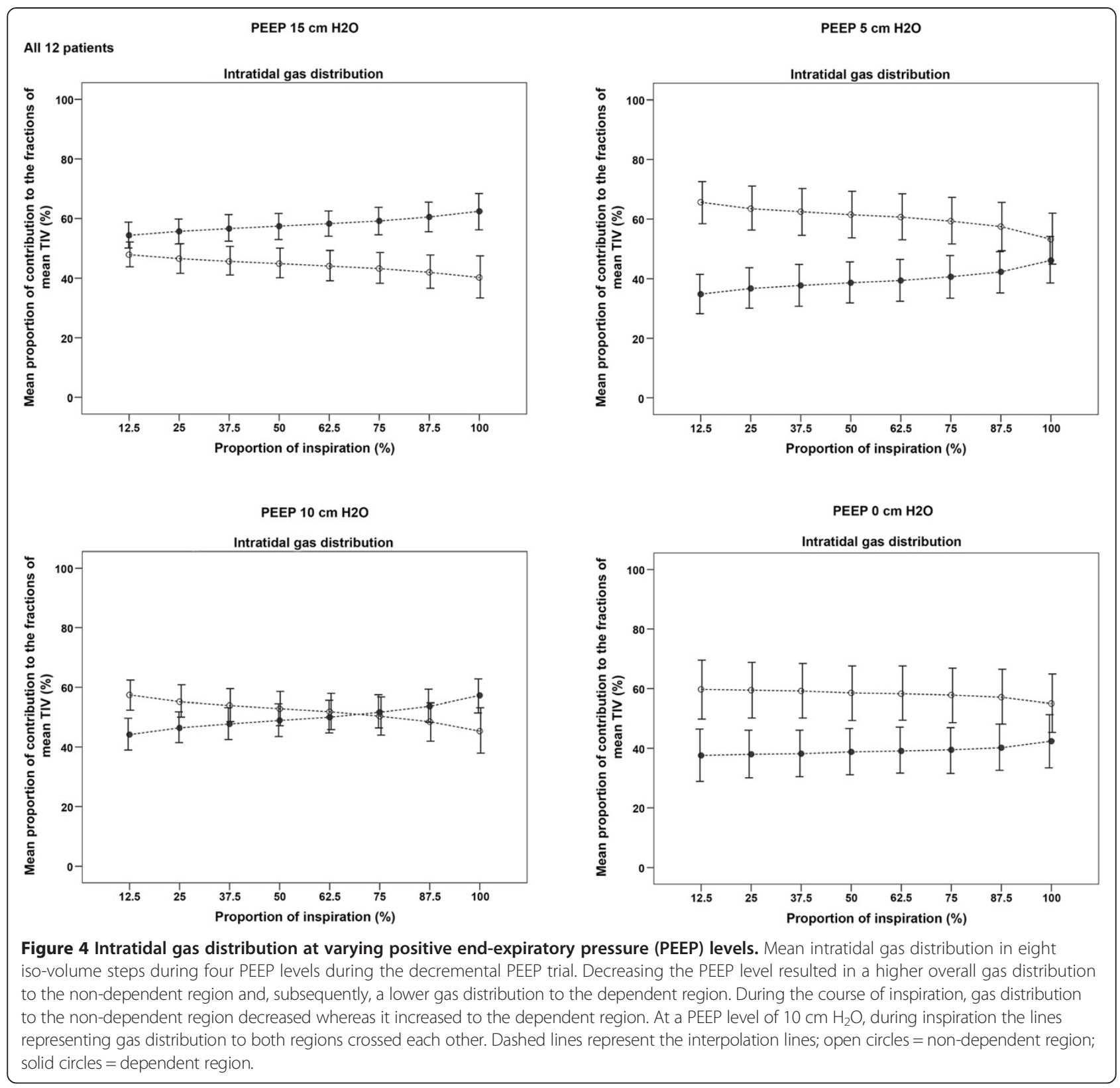

region. At a PEEP level of $10 \mathrm{~cm} \mathrm{H}_{2} \mathrm{O}$, the intratidal gas distribution curves of both regions crossed each other during a breath (Figure 4). Figure 5 shows the calculated ITV index as percentage of 1 for each PEEP level in each individual patient. There was a correlation between the $\mathrm{PaO}_{2} / \mathrm{FiO}_{2}$ ratio and the ITV index $(-0.762 ; P<0.001)$.

\section{Discussion}

This study demonstrates that intratidal gas distribution visualizes the best PEEP as compared with dynamic compliance in post cardiac surgery patients. In addition, the ITV index is able to determine a specific PEEP level in each individual patient, resulting in an even distribution of tidal volume to the non-dependent and dependent lung regions.
Below this specific PEEP level, the intratidal gas distribution is predominantly distributed to the non-dependent region. This indicates that, at these PEEP levels, there is less ventilation in the dependent region due to lung collapse. In contrast, at PEEP levels above this specific level, there is less ventilation in the non-dependent region indicating overdistention.

In an experimental study, Protti et al. showed that ventilation with high tidal volumes, resulting in an expiratory volume of 1.5 times FRC (equal to a strain of 1.5), caused severe lung edema; all their study animals died within the observation period of $54 \mathrm{~h}$ [22]. In a second study, the authors ventilated all animals with a strain of 2.5 and showed that high tidal volumes with a low level of 


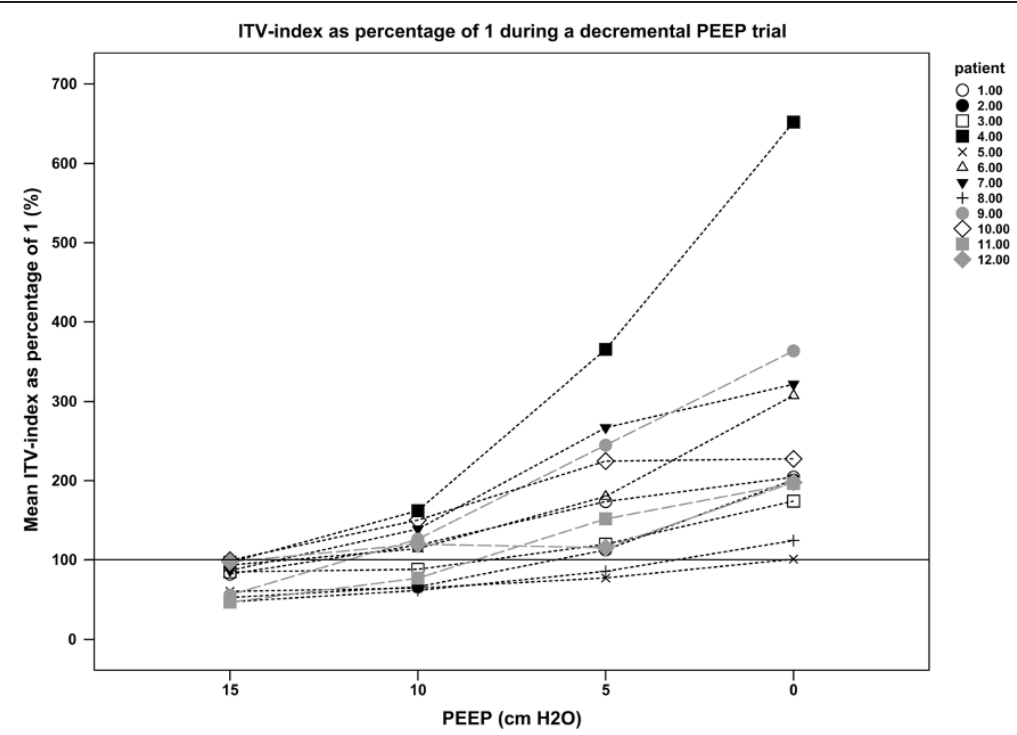

Figure 5 Intratidal gas distribution (ITV) index at varying positive end-expiratory pressure (PEEP) levels for the individual patients. Mean ITV index is shown as a percentage of 1. Here, the value 100\% indicates that both lung regions are equally ventilated. Values $>100 \%$ indicate that ventilation is predominantly distributed to the non-dependent region whereas values $<100 \%$ indicate that the dependent lung region is predominantly at that PEEP level.

PEEP damaged the lungs and increased mortality, whereas high PEEP levels together with low tidal volume but with the same strain of 2.5, did not result in edema and all animals in this group survived [23]; it was suggested that application of high PEEP levels might lead to more homogeneous lung ventilation. In 1970, Mead et al. estimated that forces acting on lung tissue increase with a factor 4.5 when lungs are inhomogeneously ventilated [24]. This was recently confirmed by Rausch et al. who performed x-ray tomographic microscopy (generating detailed three-dimensional alveolar geometry) in rat lungs and found local strain values four times the global strain [25]. Therefore, a parameter that describes the ventilation distribution could be of importance in finding the best PEEP in patients with acute respiratory distress syndrome (ARDS).

Intratidal gas distribution was first described by Löwhagen et al. who used this technique in 16 volumecontrolled ALI/ARDS patients to describe ventilation distribution to different lung regions within an inspiration [14]; they found that the intratidal gas distribution of the dorsal and mid-dorsal regions increased at higher PEEP levels, indicating redistribution of ventilation to the dependent region [14]. We modified their analysis by combining the ventral and mid-ventral regions into a non-dependent region and their mid-dorsal and dorsal regions into a dependent region [26]. Previously, we used the intratidal gas distribution technique to assess the effect of different assist levels during pressure support ventilation (PSV) and neurally adjusted ventilatory assist (NAVA) on ventilation distribution. We demonstrated that NAVA improved ventilation of the dependent lung region compared with PSV, leading to a more homogeneous ventilation of the lung [26]. In that study using the intratidal gas distribution technique, we demonstrated for the first time, less over-assistance during NAVA whereas there was marked over-assistance at higher pressure support levels [26]. This latter finding indicates that PSV with higher support levels mimics control ventilation with predominantly ventilation of the non-dependent lung. We also used the intratidal gas distribution in an experimental study comparing global and regional parameters to detect best PEEP in healthy and in ARDS lungs [27]. In these animals we found the same trend as in the present study, that is, that the intratidal gas distribution curves of the dependent and non-dependent regions reached each other at a specific PEEP level. Below this specific PEEP level, ventilation is mainly distributed to the non-dependent lung and above this level ventilation is mainly distributed to the dependent lung region. Above this specific PEEP level ventilation distribution to the non-dependent lung region diminished at higher PEEP levels, indicating that this region is overdistended.

In the present study we used a decremental PEEP trial and, as long as the PEEP level is adequate to keep the dependent lung region open, the used pressure amplitude of around $10 \mathrm{~cm} \mathrm{H}_{2} \mathrm{O}$ was sufficient to ventilate this region; however, after collapse the inspiratory pressures are too low to open up this dependent region. This indicates that ventilation distribution to the dependent lung will be improved if higher inspiratory pressures are used.

To make the intratidal gas distribution an easy-to-use parameter at the bedside, we introduced the ITV index. An 
ITV index of 1 indicates homogeneous distribution of tidal volume to the non-dependent and dependent lung regions. The intratidal gas distribution shows the behavior of the distribution of tidal volume during one breath. Figure 5 illustrates the ITV index, in which 100\% indicates an ITV index of 1 , that is, an equal distribution of ventilation to the dependent and non-dependent lung regions.

To test whether the intratidal gas distribution reliably defines the optimal PEEP, we compared the optimal PEEP values defined by the intratidal gas distribution, $\mathrm{PaO}_{2} / \mathrm{FiO}_{2}$ ratio and dynamic compliance. We found a negative correlation between the $\mathrm{PaO}_{2} / \mathrm{FiO}_{2}$ ratio and the ITV index. A lower ITV index means that more tidal ventilation is distributed to the better perfused dependent lung region, leading to less shunt and improved $\mathrm{PaO}_{2} /$ $\mathrm{FiO}_{2}$ ratio. In contrast, we found no correlation between ITV and dynamic compliance. Alveoli that open up during inspiration but collapse during expiration give higher compliance values, whereas this cyclic collapse is harmful to the lung. In addition, recruitment of a lung region, but collapse in another lung region at the same time, will not increase dynamic compliance of the entire lung. This latter effect can be visualized by regional or pixel compliance from EIT. Costa et al. introduced the regional or pixel compliance based on EIT measurements during a decremental PEEP trial in two patients with pneumonia [12]. These patients were ventilated with PCV using a constant pressure amplitude and the change in impedance represents the change in volume; thus, for each pixel the compliance could be calculated. The highest compliance at a specific PEEP level was indicated as the best PEEP. Above this PEEP value, compliance decreased due to over-distention and below this value compliance decreased due to collapse. The authors showed that the optimal PEEP level was different for the dependent and non-dependent region [12]. Also, in their experimental study, Dargaville et al. demonstrated that ventral, medial and dorsal lung regions have different optimal PEEP levels based on regional compliance values in both normal and surfactant-depleted lungs [28]. This was confirmed by our results, in which the best PEEP level for the nondependent and dependent regions were 5 and $15 \mathrm{~cm}$ $\mathrm{H}_{2} \mathrm{O}$, respectively (Figure $2 \mathrm{~B}$ ).

In accordance with our previous studies [16,29], we found more ventilation of the dependent region at higher PEEP levels, as described by the parameter COV (Figure 2D). COV describes the ventilation distribution in the ventral-to-dorsal direction and a value of $50 \%$ reflects an even distribution [13]. Thus, COV provides information about the optimal distribution of tidal volume to the non-dependent and dependent regions at a certain PEEP level, but it does not give information about collapse or overdistention during a breath, as is seen with the intratidal gas distribution.
The RVD was developed to assess the homogeneity of aeration of the lung regions $[15,19]$ during a slow inflation maneuver. It has been demonstrated in pigs that ALI lungs are more inhomogeneous compared with healthy lungs [21]; however, application of higher PEEP levels improved the homogeneity of lung ventilation. In addition, the authors showed that the dependent region was slower inflated as compared with the non-dependent region, indicating inhomogeneous ventilation of the dorsal lung parts; however, they used the SDs of the RVD index to create a ventilation homogeneity map [21]. In the present study we calculated the time needed to reach a threshold of $40 \%$ of the regional impedance change compared with the total inspiratory time and without the use of a slow flow inflation. We found that RVD values in both lung regions increased at each decremental PEEP step. Therefore, we were unable to detect the best PEEP level by means of RVD, with the used PEEP levels. However, Wrigge et al. described that RVD could only be used during a slow flow inflation maneuver with a tidal volume of $12 \mathrm{~mL} / \mathrm{kg}$ to describe tidal recruitment [15]. Therefore, in the present study the results of the RVD are incorrect. Another index to describe homogeneous ventilation is the GI index, which quantifies the variation in tidal ventilation distribution $[20,21]$ and shows the lowest value in healthy patients and the highest value in patients with ARDS [21]. However, because this index describes homogeneity based on differences in measured impedance, the index value does not take into account the presence of atelectasis or overdistention and, therefore, we believe that this is not an appropriate index. As within our range of PEEP levels we were unable to detect an optimal PEEP level based on the GI index and RVD index, it is possible that an optimum may have been found if higher PEEP levels had been applied than used in the present study.

This study has some limitations. First, EIT measures ventilation distribution in a lung slice of approximately 5 to $10 \mathrm{~cm}[30,31]$; therefore, information gathered by EIT has a limited external validity for the remaining lung tissue. However, placing the EIT belt at a higher position is known to reduce the probability to detect inhomogeneity of the lungs at decreasing PEEP levels [16] and, thus, the probability to detect lung areas susceptible to the development of VILI. Therefore, we placed the EIT belt just above the diaphragm to increase the probability of detecting lung collapse.

Second, based on the protocol of our study described previously, EIT measurements were not recorded continuously [16]. However, by treating the EIT data as percentages (instead of absolute values) the baseline shifts are corrected. In addition, the EIT belt was not disconnected from the patient to measure the same lung slice during each measurement. Third, this study was performed with post cardiac surgery patients who respond well to a 
recruitment maneuver. However, Reis Miranda et al. demonstrated that a PEEP level of $15 \mathrm{~cm} \mathrm{H}_{2} \mathrm{O}$ was necessary to keep the lung open $\left(\mathrm{PaO}_{2} / \mathrm{FiO}_{2}>350 \mathrm{mmHg}\right)$ in cardiac surgery patients [32]; the authors also showed that if patients are ventilated according to the open lung concept, fewer cytokines are released, FRC recovers faster, less oxygen is required in the normal ward, and that afterload of the right ventricle is lower in these patients [32-35]. Despite the fact that adequate PEEP settings are also important in cardiac surgery patients, most patients in need of a recruitment maneuver in combination with the best PEEP are ARDS patients. However, ARDS patients show less response to a recruitment maneuver compared with cardiac surgery patients, due to fewer gravitational-dependent infiltrates. Particularly in ARDS patients it is important to achieve homogeneous ventilation to reduce the stress acting on lung tissue. Our earlier experimental study showed the same trend of tidal ventilation distribution during a decremental PEEP trial in both ARDS-induced and healthy lungs [27]. However, additional studies are required to test whether application of this specific PEEP level leads to better outcome and also to confirm the present findings in patients with ARDS.

\section{Conclusion}

The ITV index was comparable with dynamic compliance to indicate the best PEEP level in post cardiac surgery patients. The intratidal gas distribution is able to identify the onset of over-distention in the nondependent part and recruitment in the dependent part. We believe that the ITV index may be the ideal bedside tool to detect the best PEEP; however, its preventive effect on ventilator-induced lung injury (VILI) and thereby on outcome still needs to be examined in patients with ALI/ARDS.

\section{Key messages}

- Several EIT parameters have recently been developed to optimize ventilator settings.

- Tidal impedance variation, regional compliance and ventilation surface area showed different optimal PEEP levels for the dependent and non-dependent lung regions.

- The intratidal gas distribution is able to detect the onset of alveolar overdistention and collapse, within one inspiration.

- Best PEEP as defined by the intratidal gas distribution shows good agreement with best PEEP as defined by the global parameter dynamic compliance.

- Equal distribution of ventilation to the dependent and non-dependent lung regions, as defined by the intratidal gas distribution, might lower stress and strain in the lung.

\section{Abbreviations}

ALI: acute lung injury; ANOVA: analysis of variance; ARDS: acute respiratory distress syndrome; COV: center of ventilation; CT: computed tomography; EIT: electrical impedance tomography; $\mathrm{FiO}_{2}$ : inspired oxygen fraction; FRC: functional residual capacity; Gl index: global inhomogeneity index; ITV index: intratidal gas distribution index; NAVA: neurally adjusted ventilatory assist; $\mathrm{PaO}_{2}$ : partial arterial oxygen pressure; $\mathrm{PCV}$ : pressurecontrolled ventilation; PEEP: positive end-expiratory pressure; PIP: peak inspiratory pressure; PSV: pressure support ventilation; RVD index: regional ventilation delay index; TIV: tidal impedance variation; VILI: ventilator-induced lung injury; VSA: ventilation surface area.

\section{Competing interests}

PB: the author declares that he has no competing interests. DH: the author declares that he has no competing interests. EGJ: the author declares that he has no competing interests. DG: received fees from Draeger for oral presentations.

\section{Authors' contributions}

PB: carried out the data acquisition, data processing, data analysis, and statistical analysis and participated in drafting the manuscript. DH: carried out statistical analysis and participated in drafting the manuscript. EGJ: carried out the data analysis and participated in drafting the manuscript. DG: participated in data acquisition and drafting the manuscript. All authors read and approved the final version of the manuscript.

\section{Acknowledgments}

DG received fees from Draeger for oral presentations. The study has been funded with money from the department, which had no influence on the design, collection, interpretation of data, writing the manuscript, and in the decision to submit the manuscript for publication. The authors like thank Laraine Visser-Isles for English-language editing. Financial support: this study was funded by the Department of Adult Intensive Care ${ }^{1}$, Erasmus MC Rotterdam, The Netherlands.

\section{Author details}

'Department of Intensive Care Adults, Erasmus MC Rotterdam, Room H623, 's Gravendijkwal 230, Rotterdam 3015 CE, The Netherlands. ${ }^{2}$ Department of Intensive Care, Maasstad Hospital, Maasstadweg 21, Rotterdam 3079 DZ, The Netherlands. ${ }^{3}$ Institute of Technical Medicine, University of Twente,

Drienerlolaan 5, Enschede 7522 NB, The Netherlands.

Received: 11 August 2013 Accepted: 1 May 2014

Published: 10 May 2014

\section{References}

1. Gattinoni L, Carlesso E, Caironi P: Stress and strain within the lung. Curr Opin Crit Care 2012, 18:42-47.

2. Suter PM, Fairley B, Isenberg MD: Optimum end-expiratory airway pressure in patients with acute pulmonary failure. N Engl J Med 1975, 292:284-289.

3. Tusman G, Suarez-Sipmann F, Bohm SH, Pesch T, Reissmann H, Meschino G, Scandurra A, Hedenstierna G: Monitoring dead space during recruitment and PEEP titration in an experimental model. Intensive Care Med 2006, 32:1863-1871.

4. Suarez-Sipmann F, Bohm SH, Tusman G, Pesch T, Thamm O, Reissmann H, Reske A, Magnusson A, Hedenstierna G: Use of dynamic compliance for open lung positive end-expiratory pressure titration in an experimental study. Crit Care Med 2007, 35:214-221.

5. Carvalho AR, Jandre FC, Pino AV, Bozza FA, Salluh J, Rodriques R, Ascoli FO, Giannella-Neto A: Positive end-expiratory pressure at minimal respiratory elastance represents the best compromise between mechanical stress and lung aeration in oleic acid induced lung injury. Crit Care 2007, 11:R86.

6. Maisch S, Reissmann H, Fuellekrug B, Weismann D, Rutkowski T, Tusman G, Bohm SH: Compliance and dead space fraction indicate an optimal level of positive end-expiratory pressure after recruitment in anesthetized patients. Anesth Analg 2008, 106:175-181.

7. Henzler D, Mahnken AH, Wildberger JE, Rossaint R, Gunther RW, Kuhlen R: Multislice spiral computed tomography to determine the effects of a recruitment maneuver in experimental lung injury. Eur Radiol 2006, 16:1351-1359. 
8. Pelosi P, Rocco PR, de Abreu MG: Use of computed tomography scanning to guide lung recruitment and adjust positive-end expiratory pressure. Curr Opin Crit Care 2011, 17:268-274.

9. Frerichs I, Hinz J, Herrmann P, Weisser G, Hahn G, Dudykevych T, Quintel M, Hellige G: Detection of local lung air content by electrical impedance tomography compared with electron beam CT. J App/ Physiol 2002, 93:660-666.

10. Meier $T$, Luepschen $H$, Karsten J, Leibecke $T$, Grossherr M, Gehring $H$, Leonhardt S: Assessment of regional lung recruitment and derecruitment during a PEEP trial based on electrical impedance tomography. Intensive Care Med 2008, 34:543-550.

11. Victorino JA, Borges JB, Okamoto VN, Matos GF, Tucci MR, Caramez MP, Tanaka H, Sipmann FS, Santos DC, Barbas CS, Carvalho CR, Amato MB: Imbalances in regional lung ventilation: a validation study on electrical impedance tomography. Am J Respir Crit Care Med 2004, 169:791-800

12. Costa EL, Borges JB, Melo A, Suarez-Sipmann F, Toufen C Jr, Bohm SH, Amato MB: Bedside estimation of recruitable alveolar collapse and hyperdistension by electrical impedance tomography. Intensive Care Med 2009, 35:1132-1137.

13. Frerichs I, Dargaville PA, van Genderingen $H$, Morel DR, Rimensberger PC: Lung volume recruitment after surfactant administration modifies spatial distribution of ventilation. Am J Respir Crit Care Med 2006, 174:772-779.

14. Lowhagen K, Lundin S, Stenqvist O: Regional intratidal gas distribution in acute lung injury and acute respiratory distress syndrome assessed by electric impedance tomography. Minerva Anestesiol 2010, 76:1024-1035.

15. Wrigge H, Zinserling J, Muders T, Varelmann D, Gunther U, von der Groeben C, Magnusson A, Hedenstierna G, Putensen C: Electrical impedance tomography compared with thoracic computed tomography during a slow inflation maneuver in experimental models of lung injury. Crit Care Med 2008, 36:903-909.

16. Bikker IG, Preis C, Egal M, Bakker J, Gommers D: Electrical impedance tomography measured at two thoracic levels can visualize the ventilation distribution changes at the bedside during a decremental positive end-expiratory lung pressure trial. Crit Care 2011, 15:R193.

17. Adler A, Amyot R, Guardo R, Bates JH, Berthiaume Y: Monitoring changes in lung air and liquid volumes with electrical impedance tomography. J Appl Physiol 1997, 83:1762-1767.

18. Frerichs I, Hahn G, Schiffmann H, Berger C, Hellige G: Monitoring regional lung ventilation by functional electrical impedance tomography during assisted ventilation. Ann NY Acad Sci 1999, 873:493-505.

19. Muders T, Luepschen H, Zinserling J, Greschus S, Fimmers R, Guenther U, Buchwald M, Grigutsch D, Leonhardt S, Putensen C, Wrigge H: Tidal recruitment assessed by electrical impedance tomography and computed tomography in a porcine model of lung injury. Crit Care Med 2012, 40:903-911.

20. Zhao Z, Moller K, Steinmann D, Frerichs I, Guttmann J: Evaluation of an electrical impedance tomography-based Global Inhomogeneity Index for pulmonary ventilation distribution. Intensive Care Med 2009, 35:1900-1906.

21. Zhao Z, Steinmann D, Frerichs I, Guttmann J, Moller K: PEEP titration guided by ventilation homogeneity: a feasibility study using electrical impedance tomography. Crit Care 2010, 14:R8.

22. Protti A, Cressoni M, Santini A, Langer T, Mietto C, Febres D, Chierichetti M, Coppola S, Conte G, Gatto S, Leopardi O, Masson S, Lombardi L, Lazzerini M, Rampoldi E, Cadringher P, Gattinoni L: Lung stress and strain during mechanical ventilation: any safe threshold? Am J Respir Crit Care Med 2011, 183:1354-1362.

23. Protti A, Andreis DT, Monti M, Santini A, Sparacino CC, Langer T, Votta E, Gatti S, Lombardi L, Leopardi O, Masson S, Cressoni M, Gattinoni L: Lung stress and strain during mechanical ventilation: any difference between statics and dynamics? Crit Care Med 2013, 41:1046-1055.

24. Mead J, Takishima T, Leith D: Stress distribution in lungs: a model of pulmonary elasticity. J Appl Physiol 1970, 28:596-608.

25. Rausch SM, Haberthur D, Stampanoni M, Schittny JC, Wall WA: Local strain distribution in real three-dimensional alveolar geometries. Ann Biomed Eng 2011, 39:2835-2843.

26. Blankman P, Hasan D, van Mourik MS, Gommers D: Ventilation distribution measured with EIT at varying levels of pressure support and Neurally Adjusted Ventilatory Assist in patients with ALI. Intensive Care Med 2013, 39:1057-1062
27. Bikker IG, Blankman P, Specht P, Bakker J, Gommers D: Global and regional parameters to visualize the 'best' PEEP during a PEEP trial in a porcine model with and without acute lung injury. Minerva Anestesiol 2013, 79:983-992.

28. Dargaville PA, Rimensberger PC, Frerichs I: Regional tidal ventilation and compliance during a stepwise vital capacity manoeuvre. Intensive Care Med 2010, 36:1953-1961.

29. Bikker IG, Leonhardt S, Bakker J, Gommers D: Lung volume calculated from electrical impedance tomography in ICU patients at different PEEP levels. Intensive Care Med 2009, 35:1362-1367.

30. Erlandsson K, Odenstedt H, Lundin S, Stenqvist O: Positive end-expiratory pressure optimization using electric impedance tomography in morbidly obese patients during laparoscopic gastric bypass surgery. Acta Anaesthesiol Scand 2006, 50:833-839.

31. Lindgren S, Odenstedt H, Olegard C, Sondergaard S, Lundin S, Stenqvist O: Regional lung derecruitment after endotracheal suction during volume- or pressure-controlled ventilation: a study using electric impedance tomography. Intensive Care Med 2007, 33:172-180.

32. Reis MD, Struijs A, Koetsier P, van Thiel R, Schepp R, Hop W, Klein J, Lachmann B, Bogers AJ, Gommers D: Open lung ventilation improves functional residual capacity after extubation in cardiac surgery. Crit Care Med 2005, 33:2253-2258.

33. Reis MD, Gommers D, Struijs A, Meeder H, Schepp R, Hop W, Bogers A, Klein J, Lachmann B: The open lung concept: effects on right ventricular afterload after cardiac surgery. Br J Anaesth 2004, 93:327-332.

34. Reis MD, Gommers D, Struijs A, Dekker R, Mekel J, Feelders R, Lachmann B, Bogers AJ: Ventilation according to the open lung concept attenuates pulmonary inflammatory response in cardiac surgery. Eur $J$ Cardiothorac Surg 2005, 28:889-895.

35. Reis MD, Klompe L, Mekel J, Struijs A, van Bommel J, Lachmann B, Bogers AJ, Gommers D: Open lung ventilation does not increase right ventricular outflow impedance: An echo-Doppler study. Crit Care Med 2006, 34:2555-2560.

doi:10.1186/cc13866

Cite this article as: Blankman et al:: Detection of 'best' positive endexpiratory pressure derived from electrical impedance tomography parameters during a decremental positive end-expiratory pressure trial. Critical Care 2014 18:R95.

\section{Submit your next manuscript to BioMed Central and take full advantage of:}

- Convenient online submission

- Thorough peer review

- No space constraints or color figure charges

- Immediate publication on acceptance

- Inclusion in PubMed, CAS, Scopus and Google Scholar

- Research which is freely available for redistribution 